\title{
Contaminação salivar da extrusa em novilhos alimentados com diferentes volumosos, com e sem suplementação
}

\author{
[Saliva contamination in the extrusa in steers fed with different forages, supplemented or not] \\ S.P. Gomes, M.I. Leão, S.C. Valadares Filho, M.F. Paulino \\ Departamento de Zootecnia - UFV \\ Av. P.H. Rolfs, $\mathrm{s} / \mathrm{n}$ \\ 36571-000 - Viçosa, MG
}

\begin{abstract}
RESUMO
Determinaram-se as alterações nos teores de proteína bruta (PB), compostos nitrogenados não protéicos (NNP), fibra em detergente neutro (FDN), fibra em detergente ácido (FDA), lignina (LIG), cinzas, cálcio $(\mathrm{Ca})$, fósforo $(\mathrm{P})$, magnésio $(\mathrm{Mg})$, potássio $(\mathrm{K})$ e sódio $(\mathrm{Na})$ de alimentos usados para novilhos, provocadas pela contaminação da extrusa pela saliva. Foram utilizados cinco novilhos fistulados no rúmen e esôfago, cinco dietas e cinco períodos experimentais. Os tratamentos foram: capim-elefante picado (CE), capim-elefante obtido em pastejo simulado (CES), capim-braquiária obtido em pastejo simulado (CBS), pré-secado de capim-tifton 85 (PS), feno de capim-braquiária (FB1), feno de capimtifton 85 (FT), feno de capim-braquiária e concentrado a $0,5 \%$ PV (FB2) e feno de capim-braquiária e concentrado $1,0 \%$ PV (FB3). A presença de saliva na extrusa não alterou $(\mathrm{P}>0,05)$ o teor de proteína bruta dos alimentos. Os teores de NNP foram superestimados $(\mathrm{P}<0,05)$ na extrusa em 135,0\%. Os níveis de FDN foram subestimados $(\mathrm{P}<0,05)$ em $3,4 \%$. Os níveis de FDA e LIG foram superestimados $(\mathrm{P}<0,05)$ em amostras de extrusa, em média 11,0 e $44,0 \%$, respectivamente. A contaminação por minerais foi significativa $(\mathrm{P}<0,05)$ para cinzas, $\mathrm{P}$ e Na, ocorrendo superestimativa em $31,2 \%, 116,7 \%$ e $3250,0 \%$, respectivamente. $\mathrm{O} \mathrm{Mg}$ foi subestimado $(\mathrm{P}<0,05)$ em $15,4 \%$ na extrusa.
\end{abstract}

Palavras-chave: novilho, contaminação da extrusa, saliva, volumoso, concentrado

\begin{abstract}
Alterations on the levels of crude protein (CP), non-protein nitrogen compounds (NNP), neutral detergent fiber (NDF), acid detergent fiber (ADF), lignin (LIG), ash, calcium (Ca), phosphorus $(P)$, magnesium $(\mathrm{Mg})$, potassium $(\mathrm{K})$ and sodium $(\mathrm{Na})$ of feeds used for steers, caused by the saliva contamination in the extrusa, were evaluated. Five steers, fistulated in the rumen and esophagus were fed five diets, in five experimental periods. The treatments were: chopped elephantgrass (CE), elephantgrass obtained by hand-plucked (CES), Brachiaria decumbens obtained by hand-plucked (CBS), Tifton-85 bermudagrass haylage (PS), Brachiaria decumbens hay (FB1), Brachiaria decumbens hay and concentrate at $0.5 \% \mathrm{LW}$ (FB2), and Brachiaria decumbens hay and concentrate at 1.0\% LW (FB3). The extrusa CP content was not affected $(P>0.05)$ by saliva contamination. The NNP levels were overestimated $(P<0.05)$ in the extrusa in $135.0 \%$. The NDF levels were underestimated $(P<0.05)$ in $3.4 \%$. The ADF and LIG contents were overestimated $(P<0.05)$ in extrusa samples, on average 11.0 and $44.0 \%$, respectively. The mineral contamination was significant $(P<0.05)$ for ash, $P$ and $N a$, and the levels were overestimated in 31.2, 116.7 and $3250.0 \%$, respectively. The Mg content was underestimated $(P<0.05)$ in $15.4 \%$ in the extrusa.
\end{abstract}

Keywords: steer, contamination extrusa, saliva, forage, concentrate

Recebido em 5 de maio de 2004

Aceito em 30 de agosto de 2006

E-mail: silaspg@ig.com.br 


\section{INTRODUÇ̃̃O}

Um dos principais componentes do sistema de produção bovino é a alimentação e, em especial, as pastagens, sendo fundamental o conhecimento da composição bromatológica da forrageira ingerida para $\mathrm{o}$ adequado atendimento das exigências e obtenção do desempenho almejado (Euclides, 2001).

Vários estudos demonstraram que bovinos, em pastejo, selecionam dietas resultantes em composições químicas e botânicas diferentes daquelas encontradas na forragem disponível (Euclides et al., 1992). Segundo Reid (1966), citado por Euclides et al. (1992), em razão da seletividade pelos animais, uma amostra de forragem cortada só poderia corresponder à escolhida pelos animais por acaso, tornando-se difícil a obtenção de amostras representativas da dieta selecionada pelo animal em pastejo.

Uma amostragem mais real, para avaliar o alimento consumido pelo animal em pastejo, deveria ser feita com o material que foi verdadeiramente ingerido. Isso pode ser realizado utilizando-se fístula esofágica (Van Soest, 1994). Segundo Sanchez (1993), a análise direta do pasto não é a melhor maneira de se estimar a composição química da dieta dos animais em pastejo. Porém, amostras obtidas por meio de fístulas esofágicas são contaminadas pela saliva, que contém minerais e compostos orgânicos, o que pode resultar numa composição química diferente da extrusa em relação à forragem ingerida.

A correção para essa contaminação não é simples, sendo, muitas vezes, ignorada. Os mucopolissacarídeos da saliva também interferem com a determinação da lignina (LIG), ocasionando valores elevados (Van Soest, 1994). Theurer (1970), citado por Euclides et al. (1992), enumerou vários fatores que limitam a precisão da extrusa, como: recuperação incompleta da amostra, contaminação pela saliva, mastigação e preparo a que são submetidas as amostras antes da análise. De acordo com McMeniman (1997), tempo de pastejo prolongado, para a coleta de extrusa, aumenta o risco de contaminação pela saliva.

A saliva do ruminante é rica em íons minerais, tais como sódio $(\mathrm{Na})$, potássio $(\mathrm{K})$, fosfato e bicarbonato e também em mucinas e nitrogênio, este encontrado sob a forma de uréia. A reciclagem de uréia, via saliva, é um importante fator no metabolismo nitrogenado do ruminante, sendo fonte de nitrogênio não protéico para os microrganismos ruminais (Nutrient..., 1996). Os principais componentes inorgânicos, presentes na secreção salivar da glândula parótida dos ruminantes, são o $\mathrm{Na}$, fósforo $(\mathrm{P})$ e $\mathrm{CO}_{2}$, com menores quantidades de cloro e $\mathrm{K}$, baixa quantidade de cálcio $(\mathrm{Ca})$ e magnésio $(\mathrm{Mg})$ e quantidades variáveis de nitrogênio e enxofre (Church, 1993).

No caso de animais em pastejo, é difícil a avaliação da contaminação, dada a dificuldade de se obter uma amostra idêntica à ingerida para comparação com a extrusa, impedindo, assim, que a contaminação seja determinada por diferença. Para superar esse problema, podem-se confinar os animais, o que permite total controle dos alimentos consumidos. Todavia, as condições devem ser semelhantes às encontradas em pastejo.

O trabalho foi realizado com o objetivo de determinar as alterações nos teores de proteína bruta $(\mathrm{PB})$, compostos nitrogenados, não protéicos, na forma de proteína bruta (NNP-PB), fibra em detergente neutro (FDN), fibra em detergente ácido (FDA), lignina (LIG), cinzas, $\mathrm{Ca}, \mathrm{P}, \mathrm{Mg}, \mathrm{K}$ e $\mathrm{Na}$ de alimentos usados para novilhos, provocadas pela contaminação da extrusa pela saliva.

\section{MATERIAL E MÉTODOS}

O local do experimento, os animais, as dietas utilizadas, a proporção de ingredientes nas mesmas e o manejo com os animais são mostrados por Gomes et al. (2006).

Foram usados cinco períodos experimentais, cada um com duração máxima de 13 dias, sendo sete para a adaptação às dietas, três de avaliação do consumo, digestibilidade e produção microbiana e três para a coleta de extrusa. Durante a coleta de extrusa, foram fornecidos outros volumosos além daqueles para os quais os animais haviam sido adaptados.

Os animais permaneceram em jejum por 14 horas com água à vontade, no dia anterior à coleta. A coleta de extrusa foi iniciada às oito 
horas, durando, aproximadamente, 40 minutos, através de bolsas com fundo telado, amarradas em torno da cânula esofágica. Durante o fornecimento do alimento, foram adaptados comedouros de madeira nas baias individuais, para evitar que a saliva, ao vazar através do fundo da bolsa coletora, contaminasse o alimento fornecido. Após a coleta, os animais retornavam para a alimentação normal nos comedouros de alvenaria, até às 18 horas, quando a alimentação era novamente retirada, sendo essa rotina seguida até o último dia do período.

A composição bromatológica dos volumosos, utilizados na coleta de extrusa, é apresentada na Tab.1.

Tabela 1. Composição bromatológica dos volumosos utilizados para novilhos na coleta de extrusa, de acordo com os tratamentos

\begin{tabular}{|c|c|c|c|c|c|c|}
\hline Item & $\mathrm{CE}$ & CES & CBS & PS & FB & FT \\
\hline & 9,29 & 25,35 & 27,89 & 7,32 & 5,0 & 2 \\
\hline & 13 & 9,78 & 8,90 & 15,88 & 5,32 & 12,92 \\
\hline NP-PB ${ }^{1}$ & 1,08 & 1,60 & 0,81 & 4,13 & 0,41 & 0,97 \\
\hline NP-PB ${ }^{2}$ & 13,28 & 16,36 & 9,10 & 26,00 & 7,7 & 7,51 \\
\hline inzas ${ }^{1}$ & 9,15 & 10,67 & 9,18 & 8,97 & 5,78 & 6,70 \\
\hline $\mathrm{DN}^{1}$ & 69,09 & 65,86 & 58,76 & 63,77 & 80,10 & 67,85 \\
\hline $\mathrm{DA}^{-}$ & 39,81 & 34,98 & 26,45 & 32,47 & 40,76 & 32,21 \\
\hline $\mathrm{IG}^{1}$ & 5,22 & 7,49 & 5,22 & 5,89 & 7,66 & 5,86 \\
\hline$a^{1}$ & 0,50 & 0,56 & 0,76 & 0,54 & 0,44 & 0,64 \\
\hline & 0,14 & 0,32 & 0,19 & 0,29 & 0,11 & 0,19 \\
\hline $\mathrm{Ig}^{1}$ & 0,38 & 0,26 & 0,25 & 0,23 & 0,21 & 0,33 \\
\hline & 0,82 & 0,88 & 1,06 & 1,25 & 0,75 & 0,8 \\
\hline $\mathrm{Na}^{1}$ & 0,03 & 0,03 & 0,03 & 0,03 & 0,05 & 0,03 \\
\hline \multicolumn{7}{|c|}{$\begin{array}{l}\text { im-elefante picado; CES - capim-elefante na forma } \\
\text { simulado; CBS - capim-braquiária na forma de } \\
\text { mulado; PS - pré-secado de capim-tifton } 85 ; \mathrm{FB}- \\
\text { apim-braquiária; FT - feno de capim-tifton } 85 \text {. } \\
\text { latéria seca; PB - proteína bruta; NNP-PB - } \\
\text { s nitrogenados não protéicos na forma de proteína } \\
\mathrm{N} \text { - fibra em detergente neutro; FDA - fibra em } \\
\text { ácido; LIG - lignina; Ca - cálcio; P - fósforo; Mg } \\
\text { io; K - potássio; } \mathrm{Na} \text { - sódio. } \\
{ }^{2} \% \text { da PB. }\end{array}$} \\
\hline
\end{tabular}

Nos três últimos dias do primeiro período experimental, a extrusa foi obtida do capimelefante picado (CE), do capim-elefante na forma de pastejo simulado (CES) e do capimbraquiária, também coletado em pastejo simulado (CBS).

No segundo período experimental, os animais foram alimentados com o pré-secado de capimtifton 85 (PS), e a extrusa do PS foi obtida em duas repetições nos dias 11 e 12 .
No terceiro período, os animais receberam feno de capim-braquiária (FB) durante a adaptação, e as amostras de extrusa (FB1) foram obtidas no $11^{\circ}$ e $12^{\circ}$ dia experimental. No $13^{\circ}$ dia, foi oferecido $\mathrm{O}$ feno de capim-tifton 85 (FT)e foi efetuada a coleta de extrusa.

No quarto e quinto períodos, os animais foram alimentados com FB e foram obtidas as amostras de extrusa FB2 e FB3, respectivamente. Separadamente, foram suplementados com concentrado nas proporções de 0,5\% (quarto período) e 1,0\% (quinto período) do peso vivo (PV). As extrusas FB2 e FB3 foram obtidas, em duplicatas, nos dias 11 e 12 de cada período. Os concentrados foram sempre fornecidos às $10 \mathrm{~h}$.

Dessa forma, foram obtidas oito amostras de extrusas, sendo três no primeiro período (CE, CES, CBS), uma de PS no segundo, duas de volumosos secos (FB1 e FT) no terceiro e duas de volumoso seco (FB2 e FB3) nos dois últimos períodos.

Diariamente, foi realizada a pesagem do alimento fornecido, das sobras e da extrusa armazenada na bolsa. Foram preparadas amostras compostas dos volumosos fornecidos em duplicatas, das sobras e extrusas, por animal, em dias repetidos de coleta, elaboradas com base no peso seco de cada subamostra. As análises laboratoriais são descritas por Gomes et al. (2006). Obteve-se a matéria seca (MS) ingerida pela diferença entre a MS fornecida e a MS das sobras. $\mathrm{Na}$ determinação dos nutrientes ingeridos, considerou-se que o teor desses, na MS das sobras, foi igual ao encontrado na MS ingerida devido a problemas de contaminação pela saliva, durante a coleta. Porém, acredita-se que esse procedimento tenha tido pouca influência sobre os resultados, dado o curto tempo de coleta, o que não permitia a seleção dos alimentos pelos animais. Nas amostras pré-secas, foram determinados os teores de minerais dos alimentos fornecidos, da extrusa e das sobras, conforme descrito por Silva e Queiroz (2002).

Realizaram-se amostragens da extrusa e dos alimentos, ambos in natura, para determinação do teor de NNP. As amostras foram acondicionadas em recipientes de plástico, previamente identificados, e congeladas a $-15^{\circ} \mathrm{C}$. O material foi diluído em água destilada, triturado, filtrado em gaze, tratada com ácido tricloroacético a 25\% (TCA 
$-25 \% \mathrm{P} / \mathrm{V})$, deixado em repouso por 30 minutos e então centrifugado. $\mathrm{O}$ sobrenadante foi acondicionado em recipiente de vidro e congelado a $-15^{\circ} \mathrm{C}$ para posterior determinação de nitrogênio total (Silva e Queiroz, 2002). Os teores de NNP, como proteína bruta (NNP-PB), foram obtidos pelo produto entre o teor de nitrogênio total e o fator 6,25 .

Utilizou-se o teste $\mathrm{t}$ pareado, comparando-se as diferenças entre as médias dos teores dos nutrientes no alimento oferecido e o teor na extrusa e analisando-se, separadamente ou em conjunto, os tratamentos. Cada comparação foi obtida a partir de cinco repetições (animais), avaliadas a $5 \%$ de probabilidade, utilizando-se o SAEG (Sistema..., 1995).

\section{RESULTADOS E DISCUSSÃO}

Na Tab. 2, encontram-se os teores médios de PB e de NNP-PB na MS ingerida e na extrusa coletada de novilhos, para os diferentes alimentos.

Tabela 2. Médias (\%) dos teores de proteína bruta (PB) e compostos nitrogenados não protéicos na forma de proteína bruta (NNP-PB), ingeridos (Ing) e da extrusa coletada (Ext) de novilhos, de acordo com os tratamentos

\begin{tabular}{lcccccc}
\hline \multirow{2}{*}{ Tratamento } & \multirow{n}{*}{} & \multicolumn{2}{c}{ PB (\% MS) } & & \multicolumn{2}{c}{ NNP-PB (\% MS) } \\
\cline { 7 - 7 } \cline { 6 - 7 } & & Ing & Ext & & Ing & Ext \\
\hline CE & 5 & $8,13 \mathrm{a}$ & $7,06 \mathrm{~b}$ & & $1,08 \mathrm{~b}$ & $2,73 \mathrm{a}$ \\
CES & 5 & $9,78 \mathrm{a}$ & $10,24 \mathrm{a}$ & & $1,60 \mathrm{~b}$ & $3,04 \mathrm{a}$ \\
CBS & 5 & $8,90 \mathrm{a}$ & $7,44 \mathrm{~b}$ & & $1,19 \mathrm{~b}$ & $2,50 \mathrm{a}$ \\
PS & 5 & $15,88 \mathrm{a}$ & $15,20 \mathrm{a}$ & & $4,13 \mathrm{~b}$ & $7,37 \mathrm{a}$ \\
FB1 & 5 & $5,38 \mathrm{a}$ & $5,24 \mathrm{a}$ & & $0,79 \mathrm{~b}$ & $1,74 \mathrm{a}$ \\
FT & 5 & $12,92 \mathrm{a}$ & $13,10 \mathrm{a}$ & & $0,97 \mathrm{~b}$ & $3,07 \mathrm{a}$ \\
FB2 & 5 & $5,11 \mathrm{~b}$ & $5,72 \mathrm{a}$ & & $0,21 \mathrm{~b}$ & $1,62 \mathrm{a}$ \\
FB3 & 5 & $5,48 \mathrm{a}$ & $5,64 \mathrm{a}$ & & $0,23 \mathrm{~b}$ & $1,99 \mathrm{a}$ \\
Média & 40 & $8,95 \mathrm{a}$ & $8,71 \mathrm{a}$ & & $1,28 \mathrm{~b}$ & $3,01 \mathrm{a}$ \\
\hline
\end{tabular}

Médias seguidas de letras distintas na linha diferem entre si pelo teste $\mathrm{t}$ pareado $(\mathrm{P}<0,05)$

$\mathrm{n}=$ número de observações.

CE - capim-elefante picado; CES - capim-elefante na forma de pastejo simulado; CBS - capim-braquiária na forma de pastejo simulado; PS - pré-secado de capim-tifton 85 ; FB1 feno de capim-braquiária; FT - feno de capim-tifton 85; FB2 - feno de capim-braquiária e concentrado $0,5 \%$ PV; FB3 feno de capim-braquiária e concentrado $1,0 \% \mathrm{PV}$.

Não houve diferença $(\mathrm{P}>0,05)$ no teor de $\mathrm{PB}$ da média dos tratamentos entre a MS ingerida $(8,9 \%)$ e a extrusa coletada $(8,7 \%)$. Foram observados menores valores para as extrusas do CE $(7,0 \%)$ e CBS (7,4\%). No alimento FB2, ocorreu aumento no teor de PB da extrusa $(5,1$ para 5,7\%). Para os demais alimentos, não houve diferença $(\mathrm{P}>0,05)$ entre o ingerido e a extrusa.

Euclides et al. (1992), Detmann et al. (1999) e Goes et al. (2003), ao compararem extrusa com amostras obtidas por pastejo simulado manualmente, não encontraram diferença no teor de PB entre as duas metodologias. Segundo Goes et al. (2003), a contaminação por nitrogênio salivar tenderia a elevar os teores de PB na extrusa, porém o método de secagem das amostras em estufa ventilada a $65^{\circ} \mathrm{C}$ poderia resultar na volatilização de parte do conteúdo nitrogenado da amostra. Os resultados mais baixos, encontrados na extrusa dos tratamentos $\mathrm{CE}$ e CBS, devem-se, provavelmente, à solubilização dos compostos nitrogenados, causada pela mastigação e pela saliva, perdidos por lixiviação na bolsa coletora de fundo telado e/ou por volatilização durante a pré-secagem.

Houve diferença $(\mathrm{P}<0,05)$ entre os teores de NNP-PB, na MS ingerida e na extrusa, ocorrendo maiores valores nas amostras de extrusa, devido à contaminação pela saliva. Para a determinação dos NNP-PB, foram utilizadas amostras frescas, não sendo, portanto, realizadas pré-secagens em estufa a $65^{\circ} \mathrm{C}$, o que poderia levar à perda de nitrogênio por volatilização. $\mathrm{O}$ teor de NNP-PB da extrusa foi, em média, $135,0 \%$ acima do teor encontrado na MS ingerida. A maior diferença foi observada no tratamento PS e a menor, no tratamento FB1, os volumosos com o maior $(15,9 \%)$ e o menor $(5,3 \%)$ nível protéico, respectivamente.

$\mathrm{Na}$ Tab. 3, são apresentadas as médias dos teores de FDN, FDA e LIG na MS ingerida e na extrusa, expressos em porcentagem da MS.

Considerando-se a média dos tratamentos, foram observadas diferenças $(\mathrm{P}<0,05)$ de $3,4 \% ; 11,0 \%$ e $44,0 \%$ na MS da extrusa, acima do encontrado na MS ingerida, para os três compostos, respectivamente. Os teores de FDN não diferiram $(\mathrm{P}>0,05)$ no $\mathrm{CE}, \mathrm{CBS}$ e FT. No CES, o teor de FDN da extrusa foi, em média, mais elevado que o da MS ingerida em 4,5\%, enquanto os teores do FDA e LIG na extrusa foram mais altos $(\mathrm{P}<0,05)$ em todos os tratamentos, com exceção no FB3 e CBS, que não diferiram $(\mathrm{P}>0,05)$ nos respectivos tratamentos. Segundo Van Soest (1994), valores elevados de LIG, nas amostras de extrusa, 
ocorrem devido à interferência dos mucopolissacarídeos salivares na análise. Os resultados sugerem que interferência semelhante possa ocorrer nas demais análises (FDN e FDA).

Detmann et al. (1999) observaram valor mais alto para a extrusa quanto ao teor de $\operatorname{FDN}(71,7 \%$ vs. $65,5 \%$ no pastejo simulado), atribuindo essa diferença à metodologia de amostragem. Ao comparar metodologias de amostragem, em pastagem de Brachiaria arrecta, Goes et al. (2003) encontraram conteúdos de FDN, FDA e LIG superiores na extrusa em relação ao pastejo simulado.

Foram avaliadas ainda as interferências dos componentes minerais da saliva sobre as amostras de extrusa. Na Tab. 4, são apresentadas as comparações entre a MS ingerida e MS da extrusa, para as médias dos teores de cinzas, $\mathrm{Ca}$ e $\mathrm{P}$.

Tabela 3. Médias (\%) dos teores de fibra em detergente neutro (FDN), fibra em detergente ácido (FDA) e lignina (LIG) ingeridos (Ing) e da extrusa coletada (Ext) de novilhos, de acordo com os tratamentos

\begin{tabular}{|c|c|c|c|c|c|c|c|}
\hline \multirow{2}{*}{ Tratamento } & \multirow{2}{*}{$\mathrm{n}$} & \multicolumn{2}{|c|}{ FDN (\%MS) } & \multicolumn{2}{|c|}{ FDA (\%MS) } & \multicolumn{2}{|c|}{ LIG (\%MS) } \\
\hline & & Ing & Ext & Ing & Ext & Ing & Ext \\
\hline$\overline{\mathrm{CE}}$ & 5 & $69,09 a$ & $68,52 a$ & $39,81 b$ & $43,36 a$ & $5,22 b$ & $9,15 a$ \\
\hline CES & 5 & $65,86 \mathrm{~b}$ & $68,84 a$ & $34,98 \mathrm{~b}$ & $40,20 \mathrm{a}$ & $7,49 b$ & $9,03 \mathrm{a}$ \\
\hline CBS & 5 & $58,76 \mathrm{a}$ & $62,92 \mathrm{a}$ & $26,45 b$ & $35,30 \mathrm{a}$ & $5,22 \mathrm{a}$ & $8,41 \mathrm{a}$ \\
\hline PS & 5 & $63,77 \mathrm{a}$ & $60,87 \mathrm{~b}$ & $32,47 b$ & $37,36 \mathrm{a}$ & $5,89 \mathrm{~b}$ & $8,87 \mathrm{a}$ \\
\hline FB1 & 5 & $78,58 \mathrm{a}$ & $71,55 \mathrm{~b}$ & $39,58 \mathrm{~b}$ & $42,38 \mathrm{a}$ & $7,26 \mathrm{~b}$ & $11,14 \mathrm{a}$ \\
\hline FT & 5 & $67,85 \mathrm{a}$ & $68,70 \mathrm{a}$ & $32,21 \mathrm{~b}$ & $38,74 a$ & $5,86 \mathrm{~b}$ & $10,37 \mathrm{a}$ \\
\hline FB2 & 5 & $82,25 \mathrm{a}$ & $71,79 \mathrm{~b}$ & $41,23 b$ & $43,67 a$ & $8,15 b$ & $10,52 \mathrm{a}$ \\
\hline FB3 & 5 & $79,46 \mathrm{a}$ & $72,92 b$ & $41,47 a$ & $39,29 \mathrm{a}$ & $7,57 \mathrm{~b}$ & $8,77 \mathrm{a}$ \\
\hline Média & 40 & $70,70 \mathrm{a}$ & $68,26 \mathrm{~b}$ & $36,12 b$ & $40,07 \mathrm{a}$ & $6,60 \mathrm{~b}$ & $9,51 \mathrm{a}$ \\
\hline
\end{tabular}

Médias seguidas de letras distintas na linha diferem entre si pelo teste t pareado $(\mathrm{P}<0,05)$. $\mathrm{n}=$ número de observações.

CE - capim-elefante picado; CES - capim-elefante na forma de pastejo simulado; CBS - capim-braquiária na forma de pastejo simulado; PS - pré-secado de capim-tifton 85; FB1 - feno de capim-braquiária; FT - feno de capim-tifton 85; FB2 - feno de capimbraquiária e concentrado $0,5 \% \mathrm{PV}$; FB3 - feno de capim-braquiária e concentrado $1,0 \% \mathrm{PV}$.

Tabela 4. Médias (\%) dos teores de cinzas, cálcio (Ca) e fósforo (P) ingeridos (Ing) e da extrusa coletada (Ext) de novilhos, de acordo com os tratamentos

\begin{tabular}{|c|c|c|c|c|c|c|c|}
\hline \multirow{2}{*}{ Tratamento } & \multirow{2}{*}{$\mathrm{n}$} & \multicolumn{2}{|c|}{ Cinzas (\%MS) } & \multicolumn{2}{|c|}{$\mathrm{Ca}(\% \mathrm{MS})$} & \multicolumn{2}{|c|}{$\mathrm{P}(\% \mathrm{MS})$} \\
\hline & & Ing & Ext & Ing & Ext & Ing & Ext \\
\hline$\overline{\mathrm{CE}}$ & 5 & $9,15 b$ & $10,69 a$ & $0,50 \mathrm{~b}$ & $0,56 a$ & $0,14 \mathrm{~b}$ & $0,47 \mathrm{a}$ \\
\hline CES & 5 & $10,67 a$ & $10,61 \mathrm{a}$ & $0,56 a$ & $0,49 \mathrm{a}$ & $0,32 b$ & $0,40 \mathrm{a}$ \\
\hline CBS & 5 & $9,18 b$ & $12,13 \mathrm{a}$ & $0,76 a$ & $0,71 \mathrm{a}$ & $0,19 \mathrm{a}$ & $0,36 \mathrm{a}$ \\
\hline PS & 5 & $8,97 b$ & $13,08 \mathrm{a}$ & $0,54 a$ & $0,59 \mathrm{a}$ & $0,29 b$ & $0,48 \mathrm{a}$ \\
\hline FB1 & 5 & $6,70 b$ & $8,84 a$ & $0,47 \mathrm{a}$ & $0,44 \mathrm{a}$ & $0,10 \mathrm{~b}$ & $0,37 \mathrm{a}$ \\
\hline FT & 5 & $6,70 b$ & $11,08 \mathrm{a}$ & $0,64 a$ & $0,62 \mathrm{a}$ & $0,19 b$ & $0,44 a$ \\
\hline FB2 & 5 & $4,87 b$ & $8,01 \mathrm{a}$ & $0,41 b$ & $0,47 \mathrm{a}$ & $0,11 b$ & $0,32 \mathrm{a}$ \\
\hline FB3 & 5 & $6,45 b$ & $7,91 \mathrm{a}$ & $0,45 a$ & $0,43 a$ & $0,13 b$ & $0,30 \mathrm{a}$ \\
\hline Média & 40 & $7,84 b$ & $10,29 \mathrm{a}$ & $0,54 \mathrm{a}$ & $0,54 \mathrm{a}$ & $0,18 b$ & $0,39 \mathrm{a}$ \\
\hline
\end{tabular}

Médias seguidas de letras distintas na linha diferem entre si pelo teste t pareado $(\mathrm{P}<0,05)$.

$\mathrm{n}=$ número de observações.

CE - capim-elefante picado; CES - capim-elefante na forma de pastejo simulado; CBS - capim-braquiária na forma de pastejo simulado; PS - pré-secado de capim-tifton 85; FB1 - feno de capim-braquiária; FT - feno de capim-tifton 85; FB2 - feno de capimbraquiária e concentrado $0,5 \% \mathrm{PV}$; FB3 - feno de capim-braquiária e concentrado $1,0 \% \mathrm{PV}$.

As cinzas apresentaram-se superiores $(\mathrm{P}<0,05)$ na extrusa, em média $31,2 \%$. Ocorreu diferença em todos os tratamentos, com exceção para o CES $(\mathrm{P}>0,05)$. $\mathrm{O}$ teor de $\mathrm{Ca}$ foi mais elevado $(\mathrm{P}<0,05)$ na extrusa dos alimentos CE e FB2, em $12,0 \%$ e $14,6 \%$, respectivamente. Nos demais alimentos e na média, os teores de $\mathrm{Ca}$ não foram influenciados $(\mathrm{P}>0,05)$. $\mathrm{O}$ teor de $\mathrm{P}$ foi mais alto $(\mathrm{P}<0,05)$ na extrusa de todos os tratamentos e na média, com exceção no CBS $(\mathrm{P}>0,05)$. Em média, ocorreu aumento de $116,7 \%$ no teor de $\mathrm{P}$ da extrusa, em relação à MS ingerida.

$\mathrm{Na}$ Tab. 5, são mostradas as comparações entre a MS ingerida e a MS da extrusa, para as médias dos teores de $\mathrm{Mg}, \mathrm{K}$ e $\mathrm{Na}$. 
Tabela 5. Médias dos teores de magnésio $(\mathrm{Mg})$, potássio $(\mathrm{K})$ e sódio $(\mathrm{Na})$ ingeridos (Ing) e da extrusa coletada (Ext) de novilhos, de acordo com os tratamentos

\begin{tabular}{|c|c|c|c|c|c|c|c|}
\hline \multirow{2}{*}{ Tratamento } & \multirow{2}{*}{$\mathrm{n}$} & \multicolumn{2}{|c|}{$\mathrm{Mg}(\% \mathrm{MS})$} & \multicolumn{2}{|c|}{$\mathrm{K}(\% \mathrm{MS})$} & \multicolumn{2}{|c|}{$\mathrm{Na}(\% \mathrm{MS})$} \\
\hline & & Ing & Ext & Ing & Ext & Ing & Ext \\
\hline$\overline{\mathrm{CE}}$ & 5 & $0,38 \mathrm{a}$ & $0,36 \mathrm{a}$ & $0,82 \mathrm{a}$ & $0,62 b$ & $0,03 b$ & $1,29 a$ \\
\hline CES & 5 & $0,26 \mathrm{a}$ & $0,18 \mathrm{~b}$ & $0,88 \mathrm{a}$ & $0,80 \mathrm{a}$ & $0,03 b$ & $1,28 \mathrm{a}$ \\
\hline CBS & 5 & $0,25 \mathrm{a}$ & $0,17 \mathrm{~b}$ & $1,06 a$ & $1,07 \mathrm{a}$ & $0,03 \mathrm{~b}$ & $1,24 \mathrm{a}$ \\
\hline PS & 5 & $0,23 \mathrm{a}$ & $0,22 \mathrm{a}$ & $1,25 \mathrm{~b}$ & $1,90 \mathrm{a}$ & $0,03 b$ & $1,49 a$ \\
\hline FB1 & 5 & $0,19 a$ & $0,17 \mathrm{a}$ & $0,80 \mathrm{a}$ & $0,87 \mathrm{a}$ & $0,04 \mathrm{~b}$ & $1,45 \mathrm{a}$ \\
\hline FT & 5 & $0,33 \mathrm{a}$ & $0,29 a$ & $0,80 \mathrm{~b}$ & $1,14 \mathrm{a}$ & $0,03 \mathrm{~b}$ & $1,26 \mathrm{a}$ \\
\hline FB2 & 5 & $0,22 \mathrm{a}$ & $0,17 \mathrm{~b}$ & $0,67 \mathrm{a}$ & $0,73 a$ & $0,07 \mathrm{~b}$ & $1,25 \mathrm{a}$ \\
\hline FB3 & 5 & $0,22 \mathrm{a}$ & $0,18 \mathrm{a}$ & $0,77 \mathrm{a}$ & $0,67 \mathrm{a}$ & $0,03 b$ & $1,48 \mathrm{a}$ \\
\hline Média & 40 & $0,26 \mathrm{a}$ & $0,22 b$ & $0,88 \mathrm{a}$ & $0,98 \mathrm{a}$ & $0,04 \mathrm{~b}$ & $1,34 \mathrm{a}$ \\
\hline
\end{tabular}

Médias seguidas de letras distintas na linha diferem entre si pelo teste t pareado $(\mathrm{P}<0,05)$.

$\mathrm{n}=$ número de observações.

CE - capim-elefante picado; CES - capim-elefante na forma de pastejo simulado; CBS - capim-braquiária na forma de pastejo simulado; PS - pré-secado de capim-tifton 85; FB1 - feno de capim-braquiária; FT - feno de capim-tifton 85; FB2 - feno de capimbraquiária e concentrado $0,5 \% \mathrm{PV}$; FB3 - feno de capim-braquiária e concentrado $1,0 \% \mathrm{PV}$.

O teor de Mg apresentou níveis menos elevados $(\mathrm{P}<0,05)$ nas extrusas do CES $(30,7 \%)$, do CBS $(32,0 \%)$, do FB2 $(22,7 \%)$ e na média $(15,4 \%)$. A média do teor de $\mathrm{K}$ na extrusa $(0,9 \%)$ não diferiu $(\mathrm{P}>0,05)$ daquela encontrada na MS ingerida $(0,8 \%)$, havendo diferenças $(\mathrm{P}<0,05)$ nos tratamentos $\mathrm{CE}$ (teor mais baixo na extrusa em $24,4 \%$ ), PS (média mais alta em $52,0 \%$ ) e no FT (média mais alta em 42,5\%). Os níveis de $\mathrm{Na}$ apresentaram comportamentos semelhantes aos de $\mathrm{P}$, sendo mais elevados $(\mathrm{P}<0,05)$ na extrusa de todos os tratamentos e na média geral $(3.250,0 \%)$.

Os resultados sugerem maior interferência nos níveis de cinzas, $\mathrm{P}, \mathrm{Mg}$ e $\mathrm{Na}$. A maior contaminação por $\mathrm{P}$ e $\mathrm{Na}$ ocorreu, provavelmente, devido à maior concentração desses minerais na saliva em relação aos demais, resultando em níveis mais elevados de cinzas. Os teores de $\mathrm{Ca}$ e $\mathrm{K}$ apresentaram discrepâncias relativamente pequenas devido à baixa concentração desses minerais na saliva, sendo as alterações insignificantes. Os teores de Mg mais baixo na extrusa, encontrados em alguns tratamentos, podem ser devido à ação do processo mastigatório e solubilização do $\mathrm{Mg}$ presente no alimento, sendo esse perdido através do fundo telado da bolsa, por lixiviação.

Todos os trabalhos encontrados na literatura tratam de alterações nos níveis de cinzas e não de compostos específicos. Além disso, comparam a extrusa com alimentos obtidos por outras metodologias de amostragem de dietas em pastagem, que podem apresentar erros inerentes às técnicas. Detmann et al. (1999) encontraram nível mais alto de matéria mineral na extrusa $(9,9 \%)$ em relação ao do pastejo simulado (8,3\%). Segundo McManus (1981), citado por Euclides et al. (1992), a extrusa não deve ser usada na determinação da composição mineral da dieta selecionada e, como mostrado pelos resultados, os maiores problemas ocorrem com os elementos $\mathrm{P}$ e Na.

\section{CONCLUSÕES}

A contaminação da extrusa pela saliva altera os teores de NNP, FDN, FDA, LIG, cinzas, P, Mg e $\mathrm{Na}$ em amostras obtidas por essa metodologia. Sugere-se que as análises desses compostos não sejam realizadas a partir de amostras de extrusa, ou que sejam feitas correções. De maneira geral, parece que o uso de volumoso de baixa qualidade (FB1), ou a combinação deste com diferentes quantidades de concentrado (FB2-0,5\%PV e FB3-1,0\%PV), não altera a contaminação salivar da extrusa. Assim, os resultados obtidos podem ser extrapolados para animais em pastejo, suplementados com concentrados, no período da seca.

\section{REFERÊNCIAS BIBLIOGRÁFICAS}

CHURCH, D.C. The ruminant animal digestive physiology and nutrition. Englewood Cliffs: Waveland, 1993. 564p.

DETMANN, E.; PAULINO, M.F.; ZERVOUDAKIS, J.T. et al. Avaliação qualitativa de dois métodos de amostragens de 
dieta em pastagens de capim-braquiária (Brachiária decumbens Stapf). In: REUNIÃO ANUAL DA SOCIEDADE BRASILEIRA DE ZOOTECNIA, 36., 1999, Porto Alegre. Anais... Porto Alegre: SBZ, 1999. (CD-ROM).

EUCLIDES, V.P.B. Produção intensiva de carne bovina em pasto In: SIMPÓSIO DE PRODUÇÃO DE GADO DE CORTE, 2., 2001, Viçosa. Anais... Viçosa: SIMCORTE, 2001. p.55-82.

EUCLIDES, V.P.B.; MACEDO, M.C.M.; OLIVEIRA, M.P. Avaliação de diferentes métodos de amostragem (para se estimar o valor nutritivo de forragens) sob pastejo. Rev. Bras. Zootec., v.21, p.691-702, 1992.

GOES, R.H.T.B.; MANCIO, A.B.; LANA, R.P. et al. Avaliação qualitativa da pastagem de capim Tanner-Grass (Brachiaria arrecta), por três diferentes métodos de amostragem. Rev. Bras. Zootec., v.32, p.64-69, 2003.

GOMES, S.P.; LEÃO, M.I.; VALADARES FILHO, S.C. et al. Consumo, digestibilidade e produção microbiana em novilhos alimentados com diferentes volumosos, com e sem suplementação. Arq. Bras. Med. Vet. Zootec.,v. 58, p.884-892, 2006.

McMANUS, W.R. Esophageal fistulation technique as an aid to diet evaluation grazing ruminant. In: WEELER, J.L.; MOCHRIE, R.D. (Eds.). Forage evaluation: concepts and techniques. Netley, Australia: Griffin, 1981. p. 249-260.
McMENIMAN, N.P. Methods of estimating intake of grazing animals. In: REUNIÃO ANUAL DA SOCIEDADE BRASILEIRA DE ZOOTECNIA, 34., 1997, Juiz de fora. Anais... Juiz de Fora: SBZ, 1997. p.131-168.

NUTRIENT requirements of beef cattle. 7.ed. Washington, DC: National Academy, 1996. 242p.

REID, J.T. El valor relativo de los resultados agronomicos y con animais en investigaciones sobre pasturas. In: PALADINE, O. (Ed.). Empleo de animales en las investigaciones sobre pastures. Montevideo: La Estanzuela, 1966. p.31-60.

SANCHEZ, L.J.T. Composição botânica e qualidade da dieta de novilhos esôfagofistulados em pastagem natural de Viçosa. 1993. 101f. Tese (Doutorado) - Universidade Federal de Viçosa, Viçosa, MG.

SILVA, D.J.; QUEIROZ, A.C. Análise de alimentos: métodos químicos e biológicos. Viçosa: UFV, 2002. 235p.

THEURER, C.B. Determination of botanical and chemical composition of the grazing animals diets. In: NATIONAL CONFERENCE OF FORAGE QUALITY EVALUATION AND UTILIZATION, 1970, Lincoln. Proceedings... Lincoln, Nebraska, 1970. p.j1-j17.

VAN SOEST, P.J. Nutritional ecology of the ruminant. 2.ed. Ithaca: Cornell University, 1994. 476p. 